\title{
DIGITALIZATION AND CORPORATE TRANSFORMATION: THE CASE OF EUROPEAN OIL \& GAS FIRMS
}

\author{
Jorge Fernandez-Vidal, Reyes Gonzalez, Jose Gasco, Juan Llopis, University of \\ Alicante
}

\begin{abstract}
Digital technologies have had a tremendous impact on the world and have forced companies to adapt their business models, strategies and management practices. There is a scarcity of research about digital transformation in the energy sector, so this paper aims to analyze this phenomenon in the Oil \& Gas sector through a comparative case analysis of eight market leading European Oil \& Gas companies. To ensure an adequate methodological approach, the authors have applied Eisenhardt's framework to build theories from case study research. This article relies on multiple data collection methods. 26 interviews with 18 senior executives from the sample energy firms and two global consulting firms were completed in two separate phases. To complement these interviews, information and data were collected from a range of public sources, such as newspapers, video interviews, business magazines and analyst reports, as well as public information from the eight companies under analysis, such as annual and financial reports, company presentations, regulatory filings and announcements and company news. Our research highlights several transformational moves in the firms under study that bring substantial new capabilities and allow them to achieve market-leading positions in new and digitally native business areas -although modest in size. The sample firms mainly opt for combinations of small transformational strategies to achieve their large transformation goals. However, in many organizations, digital and business transformation initiatives suffer from poor governance and are typically just a collection of unconnected activities, piecemeal strategies and pilot projects. Developing a coherent transformation strategy, with the right structure and governance, remains a challenge for most organizations. This paper, leveraging the collective learnings from the eight companies studied, aims to help decision-makers with a conceptual guideline to select the most appropriate strategic tools when undergoing a transformation, based on four dimensions that are of high relevance across multiple strategic environments.
\end{abstract}

Keywords: Digital Transformation, Business Transformation, Digital Strategy, Corporate Strategy, Energy sector.

\section{Introduction}

Digital technologies have had a tremendous impact on the world and have forced companies to adapt their business models, strategies and management practices (Bughin, LaBerge, \& Mellbye, 2017). However, this adaptation has not been homogeneous across sectors. Certain sectors are considered to be more digitally mature than others, likely as a result of the disruptive entrance of digital challengers, which has forced incumbents to transform their operations to respond to this challenge (Gupta, 2018).

Interestingly, despite its economic and industrial importance, the Oil \& Gas sector remains one of the least digitally mature markets worldwide. In a multi-year survey of more than 16,000 professionals, researchers from MIT Sloan Management Review and Deloitte found that the Oil \& Gas sector ranked $14^{\text {th }}$ out of 18 sectors in terms of digital 
maturity, far behind sectors like telecommunications, media or retail (Kane et al., 2019). The authors do not offer an explanation of why certain sectors are more digitally mature than others; however, the reality is that digital challengers have opted to disrupt industries that are less asset-heavy than the Oil \& Gas sector (Teixeira, 2019). As a result, the potential economic impact of digitalization in the sector surpasses that of most other sectors for a wide range of technologies, such as predictive maintenance (Lakhani, Iansiti, \& Herman, 2014). A study by the World Economic Forum (2017) argued that digital transformation -referring to anything from IT modernization, to digital optimization, to the invention of new digital business models- in the Oil \& Gas industry could unlock more than US $\$ 2.5$ trillion in value for the industry, its customers and the wider society.

The pressing need to digitalize their operations, coupled with the global need to reduce greenhouse gas emissions and transition to cleaner energy sources, have forced Oil \& Gas companies worldwide to rapidly transform their businesses. Consequently, Oil \& Gas companies have had to redesign their corporate strategies to digitally transform their operations and have made important moves in the digital space in the past few years (Booth, Patel, \& Smith, 2020). These organizations are substantially accelerating their digital transformation investments to adapt to a changing world; therefore, it is a very pertinent time to observe, codify and learn from their collective practices.

Such complex transformations require an ample set of strategic tools (e.g., acquisitions, alliances, strategic investments, research \& development, etc.) that should be deployed across the organization simultaneously; and such instruments differ in their appropriateness and effectiveness. While there are numerous studies that analyze the issue of digital transformation and the strategic and/or operational tools and levers companies use to implement it (Gupta, 2018; Loucks et al., 2016; Obwegeser et al., 2020; Saldanha, 2019; Wade, 2015), there are benefits in understanding in more detail the range of strategic possibilities that companies can leverage in a context of profound business uncertainty; and the Oil \& Gas sector shares a number of attributes that make it a very interesting subject for such a study.

There is a scarcity of research about digital transformation in the energy sector. There is, however, a stream of recent and emerging literature about this topic. For instance, Lu et al. (2019) looked at potential application scenarios of "Industry 4.0" technologies (e.g., big data, blockchain, wearable devices) in the Oil \& Gas industry. Hawash et al. (2020) reflected on the acceleration of digital transformation efforts in the Oil \& Gas industry during the covid-19 pandemic. Tung et al. (2020) described the digital transformation efforts of Bien Dong POC, a small affiliate of the state-owned Vietnam Oil and Gas Group. Wanasinghe et al. (2020a) analyzed how Oil \& Gas players were leveraging digital twins solutions as part of their ongoing digital transformation efforts. And Wanasinghe et al. (2020b) studied the uses and application of "Internet.of.Things" (IoT) technologies in the Oil \& Gas sector.

This paper contributes, first, to the general and growing stream of literature about digital transformation (Verhoef et al., 2021; Vial, 2019). Second, our findings contribute to the scarce but growing body of knowledge about digital transformation in the Oil \& Gas sector, by analyzing in detail the range of strategic tools leveraged by several Oil \& Gas companies in their digital transformation efforts (Lu et al., 2019; Tung et al., 2020). Third, 
it aims to make a theoretical contribution by designing and presenting a set of frameworks that could be leveraged across companies in the sector, not only in their digital transformation strategy process. Specifically, this paper studies eight market leading Oil \& Gas players in Europe: BP, Eni, Galp, Mol Group, OMV, Repsol, Shell and Total. This subset of companies has been selected because these European players share a common market and regulatory framework, have a similar business model and scope of activities and are undergoing a substantial transformation, in terms of scale and scope. The European majors' strategy contrasts with that of other global majors, such as ExxonMobil and Chevron, which remain committed to hydrocarbons (Khalaf, Raval, \& Sheppard, 2020).

This article introduces a simple framework -in the form of two matrixes presented belowthat captures the most appropriate digital transformation tools according to the company's strategic objectives, with the aim of achieving more successful transformation outcomes. It was designed after identifying, characterizing and analyzing the strategic tools used by the eight sample companies in their digital transformation efforts. Our framework was built by leveraging the collective experience and best-practices of these organizations and aims to guide decision makers in the Oil \& Gas sector -and, potentially, across industriesin their digital transformation journey.

After this introduction, the article is structured as follows: a brief review of relevant literature around digitalization and corporate transformation, with a description of the key strategic tools used by the firms in their transformation journeys, an explanation of the methodology used in the study, an analysis of the strategic tools used by the firms under analysis and the proposal of two Matrixes of Strategic Alternatives, followed by the discussion and conclusion of the article.

\section{Digital Transformation of Organizations}

The convergence and rapid development of myriad technologies, such as artificial intelligence, blockchain, digital twins, mobile, or robotic process automation, is causing a dramatic change within organizations and upending the competitive landscape across industries (Zaki, 2019). The disruptive consequences of digitalization are affecting all industries and are enabling and giving rise to new business models (Teixeira, 2019). Even if the Oil \& Gas sector has not been as affected as other industries, the impact of digitalization and, perhaps more importantly, the impact of new digitally enabled business models -such as Mobility-as-a-Service models- is being felt across the industry (Wanasinghe et al., 2020a).

The degree of complexity in digital transformations is unprecedented and represents an existential threat for most organizations (Saldanha, 2019). In fact, companies do not need to simply digitalize their operations or "become more digital" -as could have been the case with previous IT-enabled transformations- rather, they need to rewrite their business models (Zaki, 2019). Digital transformation affects all parts of the business; if, in the past, digital was the remit of Chief Information Officers and IT Departments, now it is an allencompassing force that impacts all functional and business units (Wade, 2015). As a result, the terms "digital transformation", "business transformation" or, simply, "transformation" can be used interchangeably as, in the current context, they are one and the same. As such, we will use them interchangeably throughout this article. 
To complicate things further, there is no uniform definition of the term "digital transformation" (Moroz, 2018). Out of the countless definitions that can be found in the literature, there are two concepts in particular that we consider it relevant to highlight; the first is that digital transformation refers to the "ongoing digital evolution of a company, business model, idea, process or methodology; both strategically and tactically" (Mazzone, 2014), therefore it is all encompassing, impacting all business aspects of a firm; and the second is that digital transformation is not about technology per se (Shakina, Parshakov, \& Alsufiev, 2021); it uses technology as a means, not an end, reinforcing the strategic nature of this transformation (Tabiriz et al., 2019).

Actually, most transformations today are effectively "digital business transformations", where digital technologies are used to transform business models, and improve performance; however, to be effective, organizational change is required -change that includes strategy, people and processes (Wade et al., 2019).

Our research seems to confirm the commonly held assumption that digital transformation is less about digital than it is about transformation. While technology could appear to be at times the end goal, it acts only as enabler that can assist companies in the effective transformation of their businesses. However, it is not entirely clear how organizations can implement an effective "digital/business transformation". We contribute to the filling of this gap by studying in detail the experience of the Oil \& Gas sector. We build on Wade et al.'s (2019) work -which argues that most digital business transformations focus on the "digital", when they should really focus on the "business transformation"- by analyzing which strategic tools should be used depending on a company's key transformational objectives.

\section{Strategic Tools for Digital Transformation}

Organizations look for technological and business solutions to their problems or imagine how certain emergent technologies can affect their business model. A relevant case in the Oil \& Gas sector could be the emergence and growth of new mobility trends (e.g., electric vehicles, Mobility-as-a-Service platforms, e-chargers, etc.), that affect not only the demand for Oil \& Gas products, but how Oil \& Gas players attract, interact, manage, monetize, and retain customers.

Transformation initiatives can be the result of both top-down or bottom-up processes. In a top-down process, companies identify inefficiencies or opportunities and look for technical solutions for these issues -i.e., you start with the what and move on to the how. In a bottom-up approach, companies identify or spot a new technology and ask which process, solution or application will be improved if that technology is introduced to the company's IT stack -i.e., you start with the how and define the what- (Siggelkow, \& Terwiesch, 2019). Once the technical solution is selected, companies must move on to the implementation phase. At this stage, there is no easy road map, and companies simultaneously leverage a wide range of strategic tools that, complement amplify one another, as there is no standard template or single solution that delivers what a company needs (Tabrizi et al., 2019). Interestingly, while there are some isolated studies that look at the effectiveness of certain strategic tools (e.g., Cuatrecasas, 2019; Eagar et al., 2019), we could not find any evidence about the comparative effectiveness of different strategic tools -perhaps because digital transformation programs are still work in progress in many 
organizations. Likewise, none of the organizations we studied had a systematic categorization of the transformational tools available or information on their adequacy or suitability.

Our research has identified that the eight companies we have studied use 11 different strategic tools as part of their digital transformation toolkit: 1) Legacy transformations; 2) Agile innovation; 3) Corporate Venture Builders; 4) Internal R\&D/business-driven innovation; 5) Incubators; 6) Accelerators; 7) Corporate Venture Capital; 8) Open Innovation; 9) Alliances \& Joint Ventures; 10) Mergers \& Acquisitions; and 11) Venture Capital. While these tools can be categorized across multiple dimensions, a practical way of grouping them is to differentiate between internal, mixed and external strategic tools.

Table 1 includes a brief description of each initiative. What follows is a more comprehensive explanation and review of each generic tool.

Table 1. Description of Strategic Tools identified

\begin{tabular}{|c|c|}
\hline Strategic Tools & Description \\
\hline Accelerator [Mixed] & $\begin{array}{l}\text { A space (virtual or physical) where corporations provide technical and } \\
\text { business expertise to high-growth potential startups to implement and scale-up } \\
\text { their technologies and business models applied to the corporation areas of } \\
\text { interest. }\end{array}$ \\
\hline $\begin{array}{l}\text { Agile Innovation } \\
\text { [Internal] }\end{array}$ & $\begin{array}{l}\text { Internally-driven innovation (typically with the assistance of external } \\
\text { parties/consultants) where multidisciplinary teams build digital products or } \\
\text { solutions in a highly flexible, incremental and interactive manner following } \\
\text { Agile principles. }\end{array}$ \\
\hline $\begin{array}{l}\text { Corporate Venture } \\
\text { Fund [Mixed] }\end{array}$ & $\begin{array}{l}\text { In-house fund that provides financial support and business guidance to help } \\
\text { develop and grow start-ups with a tested product, typically seeking to } \\
\text { consolidate their business and expand in existing or new markets or } \\
\text { geographies. }\end{array}$ \\
\hline Incubator [Mixed] & $\begin{array}{l}\text { A space, with support staff and equipment, where companies provide support } \\
\text { and mentorship to early-stage startups that work with corporate and external } \\
\text { experts to adapt and launch their technologies. }\end{array}$ \\
\hline $\begin{array}{l}\text { Internal (R\&D or } \\
\text { Business-driven) } \\
\text { Innovation [Internal] }\end{array}$ & $\begin{array}{l}\text { Internal } R \& D \text { innovation projects -typically of a long-term nature to develop } \\
\text { and introduce new products and services that can strengthen the company's } \\
\text { value proposition. }\end{array}$ \\
\hline $\begin{array}{l}\text { Legacy } \\
\text { Transformations } \\
\text { [Internal] }\end{array}$ & $\begin{array}{l}\text { Replacement or update of core legacy systems (e.g., adopting and } \\
\text { implementing a new ERP system) to fix structural issues, modernize the } \\
\text { business's core technical architecture and infrastructure and facilitate the } \\
\text { integration of new technological solutions. }\end{array}$ \\
\hline $\begin{array}{l}\text { Mergers \& } \\
\text { Acquisitions } \\
\text { [External] }\end{array}$ & $\begin{array}{l}\text { Direct investment and acquisitions in business, digital or technology assets } \\
\text { that provide the company with new capabilities or new business opportunities } \\
\text { or strengthen existing business lines (includes minority and majority stakes). }\end{array}$ \\
\hline
\end{tabular}




\begin{tabular}{|l|l|}
\hline $\begin{array}{l}\text { Open Innovation } \\
\text { [Mixed] }\end{array}$ & $\begin{array}{l}\text { Corporate sponsored programs, where companies leverage multiple external } \\
\text { sources (e.g., customer feedback, external agencies, university research } \\
\text { centers, etc.) to drive new innovations. }\end{array}$ \\
\hline $\begin{array}{l}\text { Alliances \& Joint } \\
\text { Ventures [Mixed] }\end{array}$ & $\begin{array}{l}\text { Strategic alliances or Joint Ventures where the participating companies pool } \\
\text { their resources to launch a new business, for which they are jointly } \\
\text { responsible. }\end{array}$ \\
\hline $\begin{array}{l}\text { Third-party Venture } \\
\text { Capital [External] }\end{array}$ & $\begin{array}{l}\text { Investment in third-party venture capital funds that provide funding and } \\
\text { business guidance to promising startups. Provides corporations with a } \\
\text { financial return (if successful) and access to this innovative ecosystem. }\end{array}$ \\
\hline $\begin{array}{l}\text { Venture Builder } \\
\text { [Internal] }\end{array}$ & $\begin{array}{l}\text { Unit that provides in-house business support to build-up new ventures, either } \\
\text { independently (with existing or newly hired staff) or partnering with startups. } \\
\text { It can be structured as a formal unit or be created ad-hoc for each new } \\
\text { business venture. }\end{array}$ \\
\hline
\end{tabular}

Source: Own elaboration

\subsection{Internal Strategic Tools}

Internal strategic tools include all tools that leverage, exclusively or primarily, a company's internal resources and/or are led by the company's employees. They might rely on third party supporters, typically outsourcers, if the company lacks the manpower or technological expertise to implement certain elements of the project. They include legacy transformations, agile innovation, Corporate Venture Builders and internal $\mathrm{R} \& \mathrm{D} /$ business-driven innovation.

Most companies rely on legacy software programs that, while critical for the running of these firms, are generally incompatible with modern technological platforms and thus limit the company's ability to digitally transform. Therefore, legacy firms embark on comprehensive legacy software modernization initiatives -most times ripping out and replacing these systems- to modernize their IT infrastructure (Deloitte, 2019). While they often leverage external technology and resources, these are core, internally led initiatives. An example of this could be Galp's implementation of a new SAP S/4HANA ERP Software (Potts, 2020).

Since the 1990s, companies have incorporated Agile models in their digital transformation strategies. Agile working models are used to implement a wide range of digital transformation activities across all sectors (Rigby, Sutherland, \& Takeuchi, 2016). They leverage cross-functional teams -that may incorporate some external outsources or advisors to complement an internal team's skills and capabilities- to design and implement digital solutions in short development cycles and with frequent releases, making it an attractive model for dynamic and fast-changing environments, such as the one we live in (De Raedemaecker et al., 2020). Examples of Agile projects include the implementation of data analytics solutions, automation or robotization of processes or the development of digital solutions like apps or websites.

Agile enjoys ample corporate support as it allows firms to limit the size of their transformation risks and adopt a "test-and-learn" mentality (Gobillot, 2016). There are 
countless examples of companies that invest in ambitious, multi-year and multi-milliondollar transformational projects or initiatives that end up failing (Crabb, 2018). Agile projects allow firms to invest in low-cost, incremental initiatives that can be constantly tested and validated (Goodpasture, 2010).

Another internal transformation initiative that is gaining some traction in the corporate world is that of Corporate Venture Building (CVB). While it is easy to group CVB with similar initiatives (such as incubators or accelerators), it specifically refers to initiatives that are designed and developed in-house, using internal resources. CVB results typically from business development initiatives or new market opportunities that are developed by the firm with the aim of launching a new business line, offering a new product or service or complementing an existing offering (Kullik et al., 2018; Scheuplein, \& Kahl, 2017). However, these initiatives are likely to fail if subject to the typical "corporate rules"; as a result, while internally-driven, they are usually run as separate units, ventures and even organizations so they are not constrained by the rules, processes and even technological architecture of the parent company (Obwegeser et al., 2020). Examples of CVB include, the creation and development of Energia Independiente by Galp (Díaz, 2020), or the incorporation and launch of Lytt and Stryde by BP's Launchpad (Lammey, 2020).

Lastly, many firms embark on Research \& Development initiatives around areas like product development and innovation or technological innovation. Many large firms are working on business model innovation initiatives in "Innovation Factories" and the like to merge a number of digital solutions and conventional offerings -typically using design thinking methodologies- to create new go-to-market strategies (Skarzynski, \& Gibson, 2008). These R\&D initiatives, which go well beyond the realm of scientific investigations, are the result of both deliberate strategies and emergent strategies. The deliberate strategy-making process is typically formal, structured and analytical; as a result of this process initiatives are approved, resources are allocated, investments are made and initiatives are executed (Christensen, \& Raynor, 2003). Emergent strategies, on the other hand, are tactical, the result of day-to-day operating decisions and more reactive in nature (Christensen, \& Raynor, 2003).

Emergent strategies are becoming increasingly relevant in organizations undergoing digital and business transformation. The rise of social media (Seidl, \& Whittington, 2014; Whittington, 2006) and digital collaboration tools within organizations (Pershina, Soppe, \& Thune, 2019) is democratizing the strategy process, no longer the domain of elite groups within companies (Hambrick, 2007), and encouraging the adoption of more participative practices and a more open strategy (Baptista et al., 2017), which naturally result in emergent strategies that are implemented alongside more traditional and deliberate ones.

Companies are also increasingly implementing internal open innovation or internal crowdsourcing initiatives, leveraging internal knowledge that may not be easily accessible due to information silos (Pohlisch, 2020). These initiatives help companies develop new emergent strategies, find new solutions to business challenges and open up new sources of innovation (Malhotra et al., 2017). In the Oil \& Gas industry, initiatives like Total's Digital Factory or OMV's Digital Intrapreneur program are good examples of such practices. 
Christensen and Raynor (2003), in a seminal work about innovation, argued that most internal innovations and transformations failed not for technological or market-driven reasons, but rather because these businesses or initiatives were given to managers or organizations whose capabilities were not up to the task. Talented and successful managers, with a strong track record in the core or stable business, tend to lack the skills to operate effectively in a new, fast-moving innovative environment (McCall, 1998). However, these "internal high-flyers", as evidenced by the literature, and confirmed by our interviews, tend to be tasked with transforming the organization or launching new ventures and struggle to succeed (Barquin et al., 2020; Christensen, \& Raynor, 2003; McCall, 1998; Nel, Furr, \& Ramsoy, 2018).

\subsection{Mixed Strategic Tools}

Mixed strategic tools include several initiatives characterized by the strategic collaboration and co-creation of digital and business solutions between internal and external actors.

Loucks et al. (2016) suggest that for companies to be "digitally business agile" -that is, to be capable of leveraging digital business models to transform and create new forms of value-, they needed to master three distinct components: hyperawareness, informed decision-making and fast execution.

Therefore, companies need to become aware of potential threats and opportunities, they need to have the right information to make good decisions on a consistent basis and they have to execute with speed and determination. Arguably, companies cannot do these things by themselves, so they resort to external actors to assist them in their innovation and transformation efforts (Kohler, 2016; Tushman, \& O'Reilly III, 2004). To do so, companies set up incubators and accelerators, create and manage Corporate Venture Capital arms, foster open innovation initiatives and enter into agreements with Strategic Partners or go a step further by creating Joint Ventures (Gutmann, 2019). These initiatives improve a company's awareness about the state of technology and how it can be applied to its business; and it helps internal actors "touch and feel" emerging technologies -and even test their application to their business (Cuatrecasas, 2019).

Incubators provide support to start-up ventures to improve their probability of survival and success and develop faster (Pauwels et al., 2016; Schwartz, 2013). The top incubators are typically independent or public organizations -backed by angel investors, venture capitalists, governments, etc. (Hoffmann, \& Radojevich-Kelley, 2012; Malek, Maine, \& McCarthy, 2014). However, several companies worldwide (e.g., BP, Shell, Total) have started their own corporate incubators to support and develop startups that can be incorporated into the company's portfolio -as an independent business, new product or service line or providing a new technological or business capability (Weiblen, \& Chesbrough, 2015). Interestingly, these firms tend to back relatively large businesses and provide them with early access to their global portfolios, which may improve their odds of survival (Mas-Verdú, Ribeiro-Soriano, \& Roig-Tierno, 2015).

Accelerators are believed to be a new generation incubation model (Pauwels et al., 2016). They have a more direct focus on accelerating the growth of startups than incubators (Bosma, \& Stam, 2012) and have a shorter duration of support than incubators, typically 
less than 6 months (Cohen, \& Hochberg, 2014). Like incubators, they try to "insource external innovation" and accelerate corporate innovation by working with start-ups (Kanbach, \& Stubner, 2016). Some corporate accelerators -such as Eni's Energizer or Shell Gamechanger- go a step further and use these programs to create a more innovative corporate culture and even attract talent (Kohler, 2016). In accelerators, start-ups get office-space, funding, mentorship, access to knowledge, support and resources commercial, technological, legal, etc.- from the corporation, with the aim of turbocharging their growth (Sahakitpinyo, 2020).

Corporate Venture Capital (CVC) arms are self-managed funds within a company's structure (Röhm, 2018) and make direct minority investments in high technology startups (Dushnitsky, 2006). CVC units give ventures access to corporate assets and capabilities (Chesbrough, 2002), technical support and funding (Maula, Autio, \& Murray, 2005). In turn, they provide corporations with access to new technologies (Dushnitsky, \& Lenox, 2005). CVC funds -such as Repsol Corporate Venture or Total Carbon Neutrality Ventures- have both financial and strategic objectives (Ernst, Witt, \& Brachtendorf, 2005). Ideally, such funding would allow the company to learn about a range of new technologies and acquire -and integrate- companies that can add more value to the company's growth and transformation efforts. However, corporations typically run these funds for financial-capital gains, without taking strategic control of their investees, thus not accruing any long-term strategic or transformational benefits (Cuatrecasas, 2019).

In the quest for new ideas to transform their businesses, companies understand that their $\mathrm{R} \& \mathrm{D}$ efforts cannot remain isolated from the rest of the world. While some companies are fiercely protective of their R\&D work and see it as a valuable strategic asset, many companies have long embraced a more open approach. Innovation requires creativity and the introduction of new concepts (Garel, 2015); and therefore, many organizations complement their in-house efforts with the power of external ideas (Chesbrough, 2003). As a result, many organizations around the world run open innovation programs -such as Shell Springboard or MOL Open Innovation Hub-, where they work with external stakeholders, such as start-ups, universities, individuals, and even competitors, to tap into their collective expertise to build stronger and better business models (Chesbrough, 2011; Deichmann, Rozentale, \& Barnhoorn, 2017). This is particularly prevalent when it comes to emergent digital technologies. Most companies are not familiar with these new technologies, but they can partner with multiple stakeholders to co-develop companyand industry-specific solutions or use cases, and do so much faster and cheaper through outside-in collaboration than by themselves (Chesbrough, 2011; Narsalay, Qiu, \& An, 2015).

It is important to highlight that these mixed strategic tools effectively combine internal and external ideas, without necessarily discriminating their precedence. Corporate incubators, accelerators, corporate venture capital arms and open innovation programs can incorporate both external startups and serve as a "development center" for ideas that are generated inside the corporation.

Despite their popularity, numerous studies suggest that in-house corporate incubators, accelerators, corporate venture capital arms and open innovation initiatives have achieved 
disappointing results (Cuatrecasas, 2019; Eagar et al., 2019; Kohler, 2016; Narsalay, Qiu, $\&$ An, 2015; Weiblen, \& Chesbrough, 2015). The reasons are multiple, such as limited impact on growth -relevant for a start-up but irrelevant for a large corporation-, long time to scale up, inadequate resourcing, cultural mismatch and poor fit with any existing business in the corporate organization (Eagar et al., 2019).

The last mixed strategic tools, strategic alliances and joint ventures, while sharing some characteristics with the above mentioned strategic tools and serving fundamentally the same business purpose -i.e., internal-external collaboration- are of a different nature.

Strategic alliances and joint ventures both pursue the same goal -that of collaborating between two or more existing organizations-; the key difference is that in a strategic alliance the two or more companies remain separate entities but in a joint venture a new entity is incorporated (Contractor, \& Lorange, 2002). In the context of corporate transformations, alliances and joint ventures bring together different parties to coordinate and share knowledge and resources that can be leveraged by both organizations (Capron, \& Mitchell, 2012).

Alliances and joint ventures can typically be a) between related partners with similar capabilities -e.g., Shell and BP-, motivated by synergies that pool resources together -for instance, to co-develop a new technology or technological application- (Thompson et al., 2012); or b) between a corporation and a partner with stronger technological capabilities -e.g., BP and Microsoft-, where they work together to co-develop company- or industryspecific solutions (Sampson, 2007).

\subsection{External Strategic Tools}

External strategic tools refer to outside-in initiatives and, among them, Mergers \& Acquisitions (M\&A) and Venture Capital investments are the most widely used instruments.

M\&A refers to the acquisition of a third-party firm, typically a full or a majority acquisition. M\&A has been widely used across the years and across sectors as a business growth and capability development tool (Bradley, Hirt, \& Smit, 2018). In the realm of digital transformation, it is becoming a very relevant strategic alternative (Cuatrecasas, 2019). In fact, a wide range of companies -even digital native giants like Amazon, Apple, Facebook, Microsoft or Google- are opting for technological acquisitions to strengthen their internal capabilities, access new business opportunities, adapt to consumer demands or enable new digital-focused business models (Cherrayil, 2020). Some experts argue that acquisitions, particularly technology acquisitions, are the only way a company can gain new capabilities and resources at scale (Cuatrecasas, 2019). Indeed, for some organizations, such as the above mentioned, technology-driven acquisitions, both large and small, are an integral part of their recurrent growth and transformation strategies (Llewellyn, 2019).

Venture Capital investments by corporations have been used for decades (Chesbrough, 2002). However, they are not as popular as "direct" M\&A, given their limited business impact. For many firms, they are seen as "play and learn" opportunities, but they are mostly treated as financial investments (Röhm, 2018). Venture Capital investments, with few exceptions, do not necessarily help the business transform -although they serve as a 
window to new and emerging technologies and business models (Cuatrecasas, 2019). As such, they are not as popular as other strategic tools and are used only by very large corporations -such as Shell or Total- in our study.

\section{Methodology}

The case study approach has become a common method in a wide range of academic disciplines (Yin, 1994). While it is true that it has been amply criticized as a research method, primarily because its findings are very situation-specific and cannot be generalized (Easton, 1995; Weick, 1969; Yin, 1994), it has gained progressive acceptance and is now regarded as a very valid research method (Dubois, \& Gadde, 2002).

The case study approach is particularly useful when trying to build new theories or reach conclusions from complex situations (Strauss, 1987). This article makes a modest theoretical contribution by presenting a conceptual framework that can be used to assist decision-makers in selecting the most appropriate strategic alternatives to digital transformation based on four separate dimensions: diversification from the core business of the firm, strategic rationale, capital requirements or desire to invest, and urgency (i.e. available to time to implement).

We have conducted a comparative case analysis (Yin, 1994) of eight European Oil \& Gas companies. We have selected these companies for our study because we wanted to analyze companies that operated in a similar business context (the European market) and regulatory context (EU regulation, so they had to comply with the same or very similar rules), were present in the same value chain (end-to-end presence, from exploration/generation to marketing), had a similar competitive position (they were all clear market leaders in their respective countries/core markets) and were undergoing a holistic transformation (both from a business and digital perspective). These companies also had different origins, business mixes and strategic capabilities, which ensures an appropriate level of disparity between companies (Eisenhardt, 1989; Flyvbjerg, 2006). To ensure an adequate methodological approach, the authors have applied Eisenhardt's (1989) framework to build theories from case study research.

An inductive research approach based on multiple case studies can achieve generalizable results (Eisenhardt, 1989). While there is no set or definitive rule, several studies argue that three to five in-depth case studies are enough to obtain acceptable results (Eisenhardt, 1989; Hoffmann \& Radojevich-Kelley, 2012). To ensure robustness and reliability, the authors have opted to study eight firms as part of this analysis. As a first step, the authors analyzed each corporate case, to understand their strategy and objectives. Then, the results of all individual analyses were compared to identify commonalities and differences, as done in previous similar studies (e.g., Kanbach, \& Stubner, 2016).

This article relies on multiple data collection methods. The authors have carried out 26 interviews with 18 senior executives from these energy firms and two global consulting firms in two separate phases (see Table 2). We deliberately selected senior executives from these eight energy firms and two prominent consulting firms who could best inform our research questions, improve our understanding of their digital transformation efforts, and contribute to our theory building efforts (Creswell, \& Creswell, 2017). All these executives worked in relevant areas for our study (e.g., Digital, Innovation, Venture Building, Strategy, etc.). During the research phase for this article, one of the authors 
headed the global transformation efforts of one of these companies, thus giving him unique insights and contacts that were leveraged for this study.

Following Bellamy et al.'s (2019) approach, respondents were asked about their awareness of specific transformational tools; if, how, and why they were used in their organization; and how effective they believed they were in transforming their organizations. Interviews were requested via email or telephone call and were conducted in person and via video calls. The authors returned to eight interviewees for additional questions. An iterative process was followed, as recommended by Morse et al. (2008), to ensure a correct understanding and interpretation of the topics discussed and ask followup questions. Lastly, we used the Glaser and Strauss (1967) model of saturation, typically labelled theoretical saturation, to determine the extent of our data collection efforts. In line with other qualitative studies, we stopped our interview/data gathering process when we felt that no additional data or insights were being found (Saunders et al., 2018).

Table 2. Summary of data collection from Phase 1 and Phase 2: Interviewees per phase

\begin{tabular}{|c|c|c|c|}
\hline No. & Title & Phase 1 & Phase 2 \\
\hline [1] & Chief Technology Officer & $\mathrm{X}$ & $\mathrm{X}$ \\
\hline [2] & Director of Transformation & $\mathrm{X}$ & $\mathrm{X}$ \\
\hline [3] & Director of Innovation & $\mathrm{X}$ & $\mathrm{X}$ \\
\hline [4] & Head of Digital Transformation & $\mathrm{X}$ & \\
\hline [5] & Director of New Business & $\mathrm{X}$ & $\mathrm{X}$ \\
\hline [6] & Head of Business Development & $\mathrm{X}$ & $\mathrm{X}$ \\
\hline [7] & Director of M\&A & $\mathrm{X}$ & \\
\hline [8] & Strategy and Transformation Manager & $\mathrm{X}$ & \\
\hline [9] & Principal Strategist & & $\mathrm{X}$ \\
\hline [10] & Venture Manager & & $\mathrm{X}$ \\
\hline [11] & Head of Portfolio Innovation & & $\mathrm{X}$ \\
\hline [12] & Industrial \& Digital Innovation Manager & & $\mathrm{X}$ \\
\hline [13] & Manager (Internal Consulting Team) & & $X$ \\
\hline [14] & Head of Strategic Analysis & & $\mathrm{X}$ \\
\hline [15] & Head of Corporate Strategy & & $\mathrm{X}$ \\
\hline [16] & Senior Manager (Consulting Firm) & $\mathrm{X}$ & $\mathrm{X}$ \\
\hline [17] & Principal (Consulting Firm) & $\mathrm{X}$ & $\mathrm{X}$ \\
\hline [18] & Partner (Consulting Firm) & $\mathrm{X}$ & $\mathrm{X}$ \\
\hline
\end{tabular}

Source: Own Elaboration

To complement these interviews, information and data were collected from a range of public sources, such as newspapers, video interviews, business magazines and analyst 
reports, as well as public information from the eight companies under analysis, such as annual and financial reports, company presentations, regulatory filings and announcements and company news.

As stated by Golafshani (2003), reliability and validity are conceptualized as trustworthiness, rigor, and quality in qualitative research. To eliminate investigator bias and increase the veracity of a social phenomenon, we must triangulate the results. The multiple data collection method, through interviews with senior executives, collection of public data from multiple sources, and iteration of interview calls, helped us perform this triangulation and increase the reliability and validity of the investigation.

\section{Digital Transformation strategies of European Oil \& Gas Firms: Matrixes of Strategic Alternatives}

Companies in the Oil \& Gas sector are in need of a big transformation -what is known as a big-T transformation-, "an intense, organization-wide program to enhance performance (an earnings improvement of 25 percent or more, for example) and to boost organizational health" (Bucy, Hall, \& Yakola, 2016). However, in many cases, small-t transformations add up to big-T transformations; therefore, a number of small transformation projects, executed successfully, help the organization self-correct over time and achieve the big transformation required (Nel, Furr, \& Ramsoy, 2018).

While our research highlights several transformation moves in the firms under study that bring substantial new capabilities and allow these companies to achieve market-leading positions in new and digitally-native business areas -e.g., BP's acquisition of Chargemaster (Vaughan, 2018); Galp's acquisition of CEIIA's mobility unit, rebranded as Flow (Silva, 2019)-, these can hardly be regarded as big-T transformations, because they do not change the firms' core business composition or materially improve their performance. They are large transformational deals within a particular business sector or segment. For instance, BP became the leading manufacturer and operator of electric vehicle chargers in the UK when it acquired Chargemaster (Vaughan, 2018); and Galp the leading mobility platform operator in Portugal when it founded its spin off the mobility business of CEiiA (Silva, 2019). However, these new businesses are relatively low impact for such business behemoths -in terms of short-term financial impact or company valuation for instance.

The firms under analysis are opting mostly for small-t transformational strategies that, when combined, are aimed at achieving their large transformation goals. As discussed, our research identified that these companies leverage 11 different strategic tools. The tools share some similarities but have major differences; they also vary substantially in terms of significance, even within a specific tool; for instance, acquisitions can vary substantially in terms of scale, investment amount, scope, and business impact.

These tools are used widely across these companies, with two caveats:

- Not all companies use all 11 tools (e.g., Galp, Mol Group or OMV do not have their own corporate venture capital fund), but all use a combination of several, if not most, tools;

- Companies maintain a different mix of strategic bets across different tools (e.g., $\mathrm{BP}$ invests prominently in new large-scale business ventures and external M\&A, 
more so than others; Repsol places huge importance on internal innovation and digital transformation through its 10 technological hubs, more aggressively than its peers).

Table 3 lists some examples of the initiatives undertaken by these firms under each strategic tool; while comprehensive, it is not meant to be exhaustive, but rather provide a perspective of the relevance of each tool across the companies under study. 
Table 3. Examples of use of Strategic Tools in the companies under study

\begin{tabular}{|c|c|c|c|c|c|c|c|c|}
\hline & & & & & & & & \\
\hline \begin{tabular}{|l} 
Strategic Tool \\
Accelerator \\
\end{tabular} & \begin{tabular}{|l|} 
BP \\
-Mobility Tech Innovation \\
Collaborative (partnership with \\
Rockerspace)
\end{tabular} & \begin{tabular}{|l} 
Eni \\
- Energizer (Joule)
\end{tabular} & $\frac{\text { Galp }}{\mathrm{NA}}$ & \begin{tabular}{|l|} 
Mol Group \\
- MoL Accelerator (with Design \\
Terminal)
\end{tabular} & \begin{tabular}{|l|} 
OMV \\
-VERBLND X Accelerator
\end{tabular} & \begin{tabular}{|l|} 
Repsol \\
- Entrepreneur Fund
\end{tabular} & \begin{tabular}{|l|} 
Shell \\
- Shell Gamechanger
\end{tabular} & \begin{tabular}{|l|} 
Total \\
- Booster
\end{tabular} \\
\hline \begin{tabular}{|l|} 
Agile Innovation \\
\end{tabular} & - Digital agile programs with Accenture & $\begin{array}{l}\text { - Digital Business Unit runs a number of } \\
\text { agile programs }\end{array}$ & - Digital agile programs with Outsystems & $\begin{array}{l}\text { s- Multiple agile projects in MOL's } \\
\text { Digitial Factory }\end{array}$ & $\begin{array}{l}\text { - Multiple initiatives ( }+200 \text { people } \\
\text { traned in Agile) }\end{array}$ & $\begin{array}{l}\text { - Multiple programs run by the Agile } \\
\text { Digital Hub }\end{array}$ & & $\begin{array}{l}\text { - Multiple agile projects in Total's } \\
\text { Digital Factory }\end{array}$ \\
\hline \begin{tabular}{|l} 
Corporate Venture \\
Fund
\end{tabular} & - BP Ventures & - Eni Next & $\mathrm{NA}$ & & & - Repsol Corporate Venturing & - Shell Ventures & -Total Carbon Neutrality Ventures \\
\hline Incubator & - Catalyst (partnership with Masdar) & - Digital Competence Center & $\mathrm{NA}$ & & & - Entrepreneur Fund & 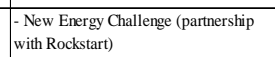 & - Plant 4.0 \\
\hline Internal Innovation & & & - Upcoming Energies Innovation facility & - MOL Digitial Factory & $\begin{array}{l}\text { - Digital Intrapreneur Program } \\
\text { - DigituP program } \\
\text { - Digitalmotion program }\end{array}$ & $\begin{array}{l}-10 \text { Digital \& I Innovation Hubs (e.g.,. } \\
\text { Data Analy lyics, Blockchain, RPA, etc) }\end{array}$ & - Shell TechWorks & \begin{tabular}{|l} 
- Total Digital Factory \\
\end{tabular} \\
\hline \begin{tabular}{|l|} 
Legacy \\
Transformations
\end{tabular} & & & $\begin{array}{l}\text {-ERP Transformation: SAP S/4HANA } \\
\text { project }\end{array}$ & & $\begin{array}{l}\text { - ERP Transformation SAP S/4HANA } \\
\text { project }\end{array}$ & & & \\
\hline \begin{tabular}{|l} 
Mergers \& \\
Acquisitions
\end{tabular} & 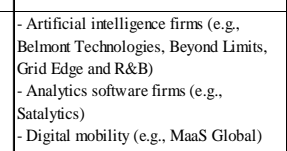 & & - Flow & -SMATRICS & & $\begin{array}{l}\text { - Advanced mobiliti (e.g, Ample, } \\
\text { DriveSmart ob Begag Motor) } \\
\text { - Energy transition firms (e.g., Wattio or } \\
\text { Ampere Energy) }\end{array}$ & $\begin{array}{l}\text { - Digital \& analytics firms (e.g., } \\
\text { Asperitas, Kespry, MachineMax or } \\
\text { Rocosole) }\end{array}$ & $\begin{array}{l}\text {-Smart energy firms (e.g., Autogrid, EG, } \\
\text { GridBeyond or Tado) } \\
\text { - New mobility firms (e.g., Chargetrip, } \\
\text { Hetecth, Scoop, Swiftly or Xee) }\end{array}$ \\
\hline Open Innovation & 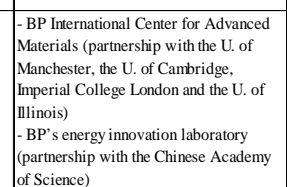 & 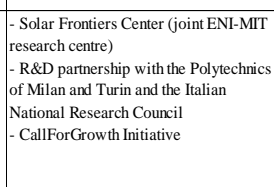 & $\begin{array}{l}\text { - ISPG - Instituto do Petroleo e Gás } \\
\text { (R\&D/Innovation partnership with the } 6 \\
\text { largest universititis in Portugal) } \\
\text {-Galp Datathon }\end{array}$ & - MOL Open Innovation Hub & $\begin{array}{l}\text {-Artificial Intelligence project } \\
\text { collaboration with Stanford University } \\
\text { '- Innovation2 Company (with the Vienna }\end{array}$ & $\begin{array}{ll} & \text { - Inspire Program } \\
\text { - Repsol Technology Lab }\end{array}$ & \begin{tabular}{|l} 
- Shell Springboard \\
- Studio X (with BCG Digital Ventures)
\end{tabular} & \\
\hline \begin{tabular}{|l}
$\begin{array}{l}\text { Alliances \& Joint } \\
\text { Ventures }\end{array}$ \\
\end{tabular} & $\begin{array}{l}\text { - Lightsource BP (strategic alliance with } \\
\text { Lightsource Renewabable nerery) } \\
\text { - Strategic partnership with Microsost on } \\
\text { digital energy innovation }\end{array}$ & & -Zero-E Spain (IV with ACS) & $\begin{array}{l}\text { - NEXT-E (alliance with BMW, Nissan, } \\
\text { Petrol, HEF and E.ON) }\end{array}$ & $\begin{array}{l}\text {-Strategic parthership with Microsoft on } \\
\text { digital \& cloud solutions }\end{array}$ & $\begin{array}{l}\text { - ILBOC (joint venture with SK) } \\
\text { - Dynasol (joint venture with the KUO } \\
\text { Group) } \\
\text { - Strategic alliance with Emerson on } \\
\text { exploration and developnent software }\end{array}$ & & 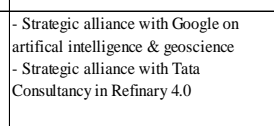 \\
\hline \begin{tabular}{|l} 
Third-party Venture \\
Capital
\end{tabular} & & & - Energy Impact Parthers & $\begin{array}{l}\text { - InnoEnergy } \\
\text { - Lead Venures }\end{array}$ & & $\begin{array}{l}\mid \text { Innoknergy } \\
\text { - Station Houston }\end{array}$ & & $\begin{array}{l}\text { - CathayCapital } \\
\text { - EComobilit Ventures } \\
\text { - idinvest Parthers } \\
\text { - NO Capital } \\
\text { - Powerhouse }\end{array}$ \\
\hline Venture Builder & \begin{tabular}{|l}
-Fotech \\
- Lyth \\
-Onyx \\
- STRYDE
\end{tabular} & & -Energia Independiente & $\begin{array}{l}\text { - MOL Limo (car sharing) } \\
\text { - MOL Bubi (bike sharing) } \\
\text { - Slovnaft BAJK (bike sharing) }\end{array}$ & & - Wible (built with KIA) & $\begin{array}{l}\text { - Shell Venture Builder (e.g., battery } \\
\text { swapping \& micro-mobility) }\end{array}$ & \\
\hline
\end{tabular}

Source: Own elaboration 
Companies rely on a wide range of strategic tools to evolve, change and constantly create value (Goold, Campbell, \& Alexander, 1994). However, good operators do not use these tools indiscriminately and there is ample research that recommends the most appropriate strategic tool for each business context (Capron, \& Mitchell, 2012). Nevertheless, when asked, none of the companies under study had a systematic methodology or framework that allowed them to select the most appropriate strategic tool -or tools- to guide their transformation efforts.

The analysis of this wide range of tools, their characteristics and potential applicability was the basis to elaborate a set of frameworks -in the form of two matrixes- that contextualized the use of each strategic tool, aiming to bridge this practical gap and assist decision-makers in selecting the most appropriate tools to transform their businesses.

The first step in our framework creation process involved asking our interviewees a straightforward yet complex question: "what dimensions matter to you when picking one strategic tool vs another?". As discussed, our interviewees did not have a structured approach, but after our back-and-forth conversations, we reached a consensus around four dimensions that appeared to be critical across all companies and strategic contexts:

- Where do I want to operate? Is it in an existing market/business model (i.e., a core market where the firm is already present) or a new one (i.e., a non-core one, one new to the firm)? [which we called, "Diversification from the core"]

- Do we have the internal resources or capabilities to operate in that market? (i.e., is this something we think we can do with what we know or have internally?) [which we called, "Resources \& Capabilities"]

- How much budget do we have for this initiative or how much do we want to spend? [which we called, "Capital Requirements"]

- When could or should the initiatives be implemented or be delivering results? [which we called, "Time to implement"]

Our next step was to determine how we could translate these dimensions into an actionable framework that was practical and easy to use. We tested four potentially suitable frameworks (i.e., matrix, issue tree, hierarchy tree and process framework) with our interviewees and concluded that matrixes were the most appropriate format, according to their feedback -among other reasons, we had four interlinked variables that fitted well into two matrixes. Furthermore, matrixes are visually appealing and easy to understand and build upon an existing collection of corporate strategy matrixes that are well-known to practitioners and researchers (Ansoff, 1965; Wind, 1974; Wright, 1978).

Selecting the right dimension for the matrixes' variables is the first and foremost step in the matrix creation process (Lowy, \& Hood, 2010). Since we had already identified the four critical dimensions, our next step was to identify the most suitable combination of axis variables to use, following the approach carried out in other studies (e.g., Calandro

\& Lane, 2007). Given the existence and usage of multiple $2 \times 2$ matrixes, we opted to develop two $2 \times 2$ matrixes to fit these four critical dimensions. 
First we plotted the four variables into the six possible combinations of $2 \times 2$ matrixes and asked interviewees to select the most appropriate combinations. The resulting combinations selected were "Diversification from the Core" and "Resources \& Capabilities" (which we called the "Strategic Management Perspective", Figure 1a) and "Capital Requirements" and "Time to Implement" (which we called the "Investment Management Perspective", Figure 1b).

Below, we provide a more detailed description of the selected variables on each matrix:

A) Strategic Management Perspective:

Diversification from the core: Measures the extent to which the initiative is linked to the core business of the firm or relates to new business areas or business models where the company was not present before.

Resources \& capabilities: Indicates whether the strategic tool intends to leverage existing resources and/or improve existing capabilities or acquire new resources \& capabilities.

B) Investment Management Perspective:

Capital requirements: Shows whether the capital requirements are considered low/medium/high. Given that the capital budgets of companies differ substantially, the definition criteria can change materially between companies (e.g., a "high" capital requirement for Mol Group, with $<\mathrm{USD} 20 \mathrm{Bn}$ in revenue, could be potentially regarded as "low" by Shell's standards, with >USD340Bn in revenue).

Time to implement: Measures the time-to-impact or time-to-maturity of each initiative. While a 1-5 year horizon seems to be most appropriate (as the companies under study rarely look beyond a 5-year horizon when it comes to transformational initiatives), it can also be adapted to the specific time frame of the company. 
Figure 1a: Matrix of Strategic Alternatives: Diversification and Resources and Capabilities

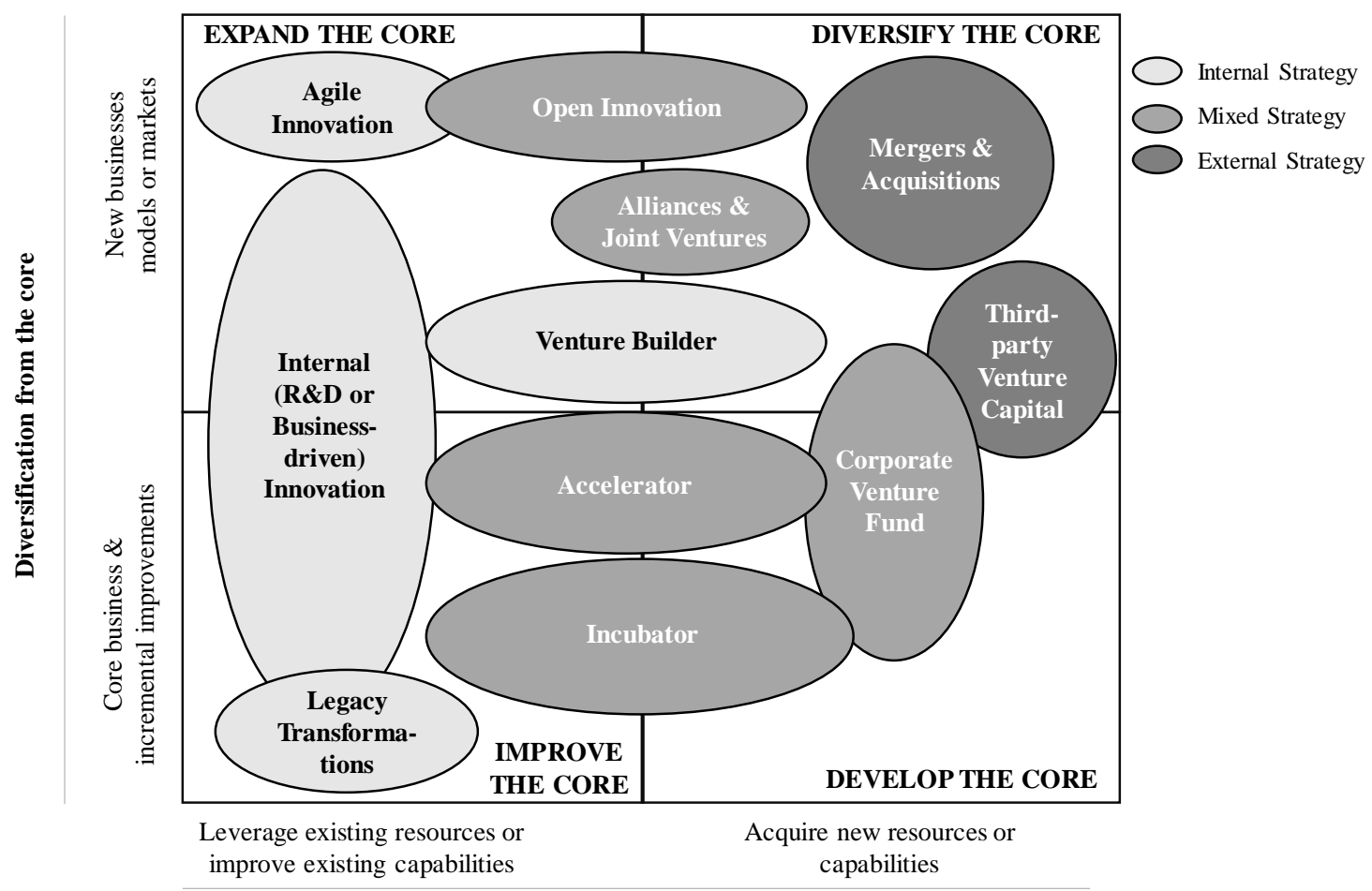

Resources \& Capabilities

Source: Own elaboration 
Figure 1b: Matrix of Strategic Alternative: Capital Requirements and Time to Implement

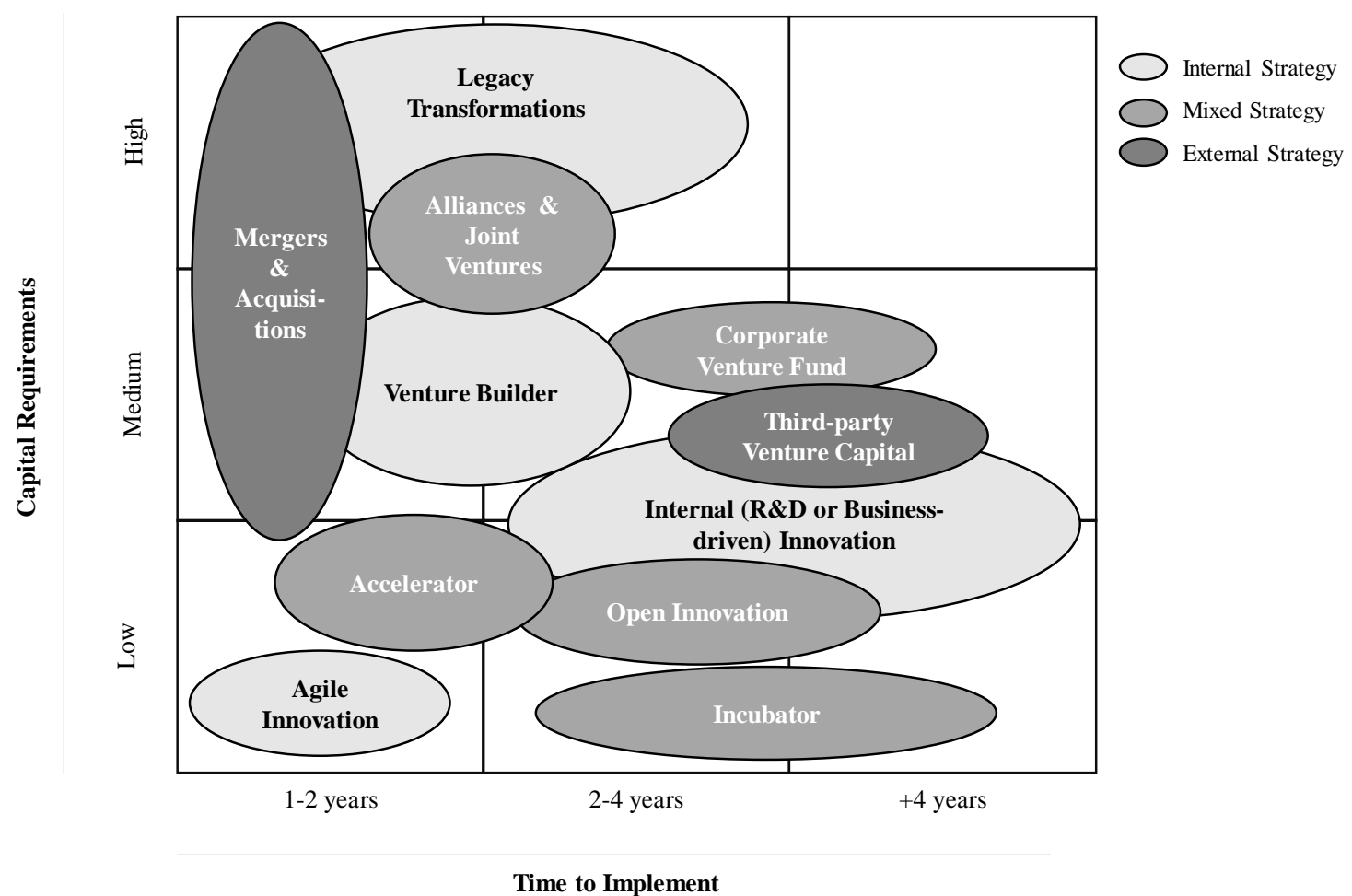

Source: Own elaboration

Once the matrixes were designed, we called upon the collective learnings and bestpractices of our interviewees -complemented by our own academic research- to plot each strategic tool within the two matrixes. The matrixes presented in this study are the result of multiple discussions and interactions with our interviewees. For each strategic tool, we considered four questions a) does this tool help a company diversify to enter new markets or business models; b) does this tool leverage existing resources or improve existing capabilities; or does it allow you to acquire or develop new ones?; c) what is the typical level of capital investment required by this strategic tool?; d) what is the implementation timing typically associated with this tool? We iterated with multiple versions of these matrixes until our interviewees validated the relative position of each strategic tool on both matrixes. The loose and intermixing shape of the strategic tools under these matrixes simply signals the versatility and complementarity of most of these tools and reflects the natural ambiguity of strategic planning and strategic frameworks (Arend, 2020).

It is important to note that these matrixes do not represent the "as-is" of these organizations (e.g., some organizations are trying to use internal innovation to diversify into new business areas), but rather they present a guideline that indicates when each strategic tool could be more suitable.

\subsection{Description and interpretation of the matrixes}

The first matrix (Figure 1a), is divided in four quadrants: 
- The lower-left-quadrant incorporates strategic tools that are used to "improve the core", that is, achieve incremental improvements in the core business, leveraging existing resources or building upon existing capabilities.

- The upper-left-quadrant includes strategic tools that aim to "expand the core", using existing resources and capabilities to enter new markets or compete with new business models.

- The lower-right-quadrant comprises strategic tools that seek to "develop the core" by acquiring new resources or capabilities in core or incremental areas.

- The upper-right-quadrant contains strategic tools that "diversify the core" through the acquisition of new resources or capabilities to enter or develop new businesses or markets

The second matrix (Figure 1b) is divided into nine boxes that help characterize each strategic tool based on their typical investment required and time to implement. In contrast to the first matrix, this second one is of a more descriptive nature and aims to denote the typical attributes of each tool.

These tools should be used in sequence, and while we advise starting with the "Strategic Management Perspective" the insights from the matrixes does not change. Figure 2 explains, by way of an example, how to practically use these matrixes.

\section{Figure 2: Example of the use of the matrixes}

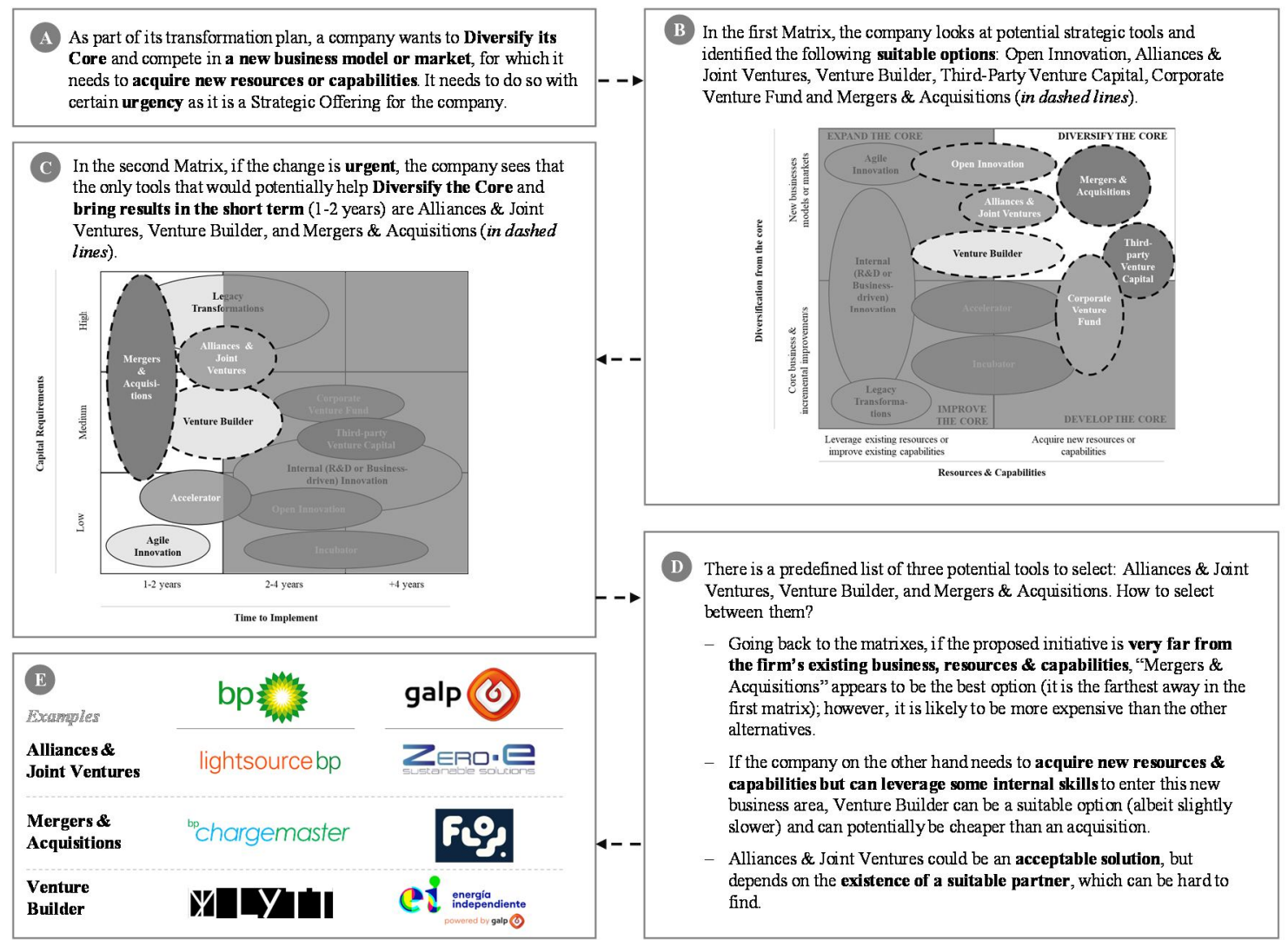




\section{Discussion and Conclusion}

In many organizations, digital and business transformation initiatives suffer from poor governance and are typically just a collection of unconnected activities, piecemeal strategies and pilot projects (Obwegeser et al., 2020). Developing a coherent transformation strategy, with the right structure and governance, remains a challenge for most organizations (Wade et al., 2019), despite being considered a critical element for any effective digital transformation (Boström, \& Celik, 2017; Desmet et al., 2015; Mhlungu, Chen, \& Alkema, 2019; Oswald, \& Kleinemeier, 2017). Our study confirms the findings of prior studies (Kane et al., 2016; Kazim, 2019): most of the interviewees say that, despite their commendable progress, their organizations have ample room for improvement in terms of digital and business transformation strategy, structure, and governance.

Consistent with other studies, we conclude that incumbent organizations -such as the subjects of our study- are hindered by digital debt from their legacy systems; but can take advantage of a range of digital opportunities in new or adjacent business areas (Rolland, Mathiassen, \& Rai, 2018; Sandberg, Mathiassen, \& Napier, 2014). As a result, many of the organizations we studied are finding ways to build digital capabilities in non-core areas (e.g., artificial intelligence, digital mobility, smart energy). However, as pointed out by Karimi and Walter (2015), it is challenging -and it requires a lot of management time and commitment- to decide whether to keep new digital business and capabilities separate or integrate them with existing ones; and we found that most of the organizations we studied were still unsure as to the future integration structure of "the old and the new".

In the same way that employees and organizations need to change their styles and waysof-working to meet the challenges associated with the execution of digital transformations (Kazim, 2019), we found that organizations need new frameworks and tools to direct their transformation efforts. While there are multiple strategic tools that aspire to help managers cope with the uncertainties of strategy making (Jarzabkowski, \& Kaplan, 2015), and some frameworks that are specifically designed to guide organizations in their digital transformation programs (e.g., Saldanha, 2019), we identified a gap in the existing literature and managerial toolkit when it comes to selecting the most appropriate choice or choices of digital transformation tools. We fill this gap by offering a potential answer in the form of two intuitive matrixes.

This article also adds to the growing stream of strategy research that examines the different affordances of strategic tools (Burke, \& Wolf, 2021; Jarzabkowski, \& Kaplan, 2015; Knight, Paroutis, \& Heracleous, 2018; Paroutis, Franco, \& Papadopoulos, 2015; Spee, \& Jarzabkowski, 2009; Wright, Paroutis, \& Blettner, 2013) and builds on the academic understanding of how strategic decisions are made, in this case, in the context of a digital transformation.

This study has implications for both practitioners and scholars.

For practitioners, this study gives an overview of the range of strategic tools to be considered when implementing a digital and/or business transformation plan. While it is 
based on the activities and tools of a subset of companies in a specific sector (major European Oil \& Gas firms), it can be argued that the study's findings can be generalized and applied, at a minimum, across companies in the energy sector. Throughout industries, digital technologies radically change the competitive landscape and customer expectations (Tijan et al., 2021); as such, the overview of the range of strategic tools offers companies of various sizes a baseline to inform and shape their transformation strategies.

This study also provides decision-makers with a conceptual guideline to select the most appropriate strategic tools when undergoing a transformation, based on four dimensions that we believe are of high relevance across multiple strategic environments. Given that most digital transformations fail to meet or exceed expectations (Obwegeser et al., 2020), practitioners should welcome any recommendations that improve their odds to effectively transform their organizations. In fact, "getting it wrong" by picking an inadequate strategic tool can delay and derail a company's digital transformation plan. Therefore, we argue that our matrixes can conceptually -but not prescriptively- help shape, or at least facilitate, the complex decision-making process of picking the right strategic tool to digitally transform an energy company. Given that these matrixes build upon a range of well-known corporate portfolio matrixes such as the BCG Matrix (Henderson, 1970) or the GE/McKinsey matrix (Wind, 1974) that are widely used in planning and strategic areas (Pidun et al., 2011), they should be intuitive and easy to use. Our interactions and validations with our interviewees seem to confirm this. In any case, as with other strategic tools, we expect practitioners to tweak these matrixes and adapt them to their unique circumstances (Burke, \& Wolf, 2021; Jarzabkowski, \& Kaplan, 2015).

For scholars, this study provides an interesting insight into a critical economic sector that is undergoing an ambitious, and much needed, transformation, as the world transitions towards cleaner energy sources (Elliott, 2020). The results of this study enrich the growing body of knowledge about the transformation of the energy sector. The overview of the strategic tools offers other scholars a comprehensive introduction to the range of strategic tools that could be used in a digital transformation program. Future studies can of course expand on this list, but we believe this can serve as an interesting starting point. Lastly, the two matrixes presented can help in the categorization and understanding of these strategic tools and can serve as a basis for deeper understanding of the successful and failed usage of these tools as part of a digital transformation plan.

This article calls for further research across a number of areas, particularly around the applicability and relative success -and key success factors- of each strategic tool. While currently most organizations opt for a simultaneous combination of tools, it is not yet known which ones are most successful in the long run or under what conditions they work or not; unfortunately, it is too early to tell, as very few companies have completed their organization-wide digital transformations (Elliot, 2017) and studies will need to be carried out post-transformation. There are studies that point to the merits of certain transformational tools; for instance, Cuatrecasas (2019) promulgates the success of technological M\&A acquisitions as a digital transformation tool; and Rigby, Sutherland, \& Takeuchi (2016) strongly believe in the merits of agile innovation. However, in the 
same way that piecemeal strategies do not work (De Armond, 2015), an isolated study of certain tools is likely to miss important insights.

Building on this analysis, the authors consider that the following open questions warrant future academic research:

- Is there any difference in the transformational impact or results of internal, mixed and external tools?

- Is there a specific business or strategic context where one set of tools is better than another?

- Should all strategic tools (or a subset of them) be used simultaneously in a transformational program; or is there a specific cadence or order that should be followed?

Digital innovations and new business models present a real challenge to most organizations, but also provide traditional companies with an endless number of opportunities (Gupta, 2018). But organizations that wish to transform need to coordinate their overall strategy with their transformation strategy and to this end, it is critical that they understand the wealth of strategic tools available to them and in what context they are more appropriate. This study contributes to this understanding and opens the door to future research analysis.

\section{Bibliography}

Ansoff I. 1965. "Corporate Strategy: An Analytic Approach to Business Policy for Growth and Expansion”. McGraw-Hill, New York, USA.

Arend RJ. 2020. "Strategic decision-making under ambiguity: a new problem space and a proposed optimization approach". Business Research, Vol. 13, pp.1231-1251.

Baptista J, Wilson AD, Galliers RD, \& Bynghall S. 2017."Social Media and the Emergence of Reflexiveness as a New Capability for Open Strategy". Long Range Planning, Vol.50, N.3, pp.322-336.

Barquin S, Dreischmeier R, Hertli S, Königsfeld J, \& Roth A. 2020. "The big boost: How incumbents successfully scale their new businesses". McKinsey \& Company, 27th August 2020. Retrieved from https://www.mckinsey.com/business-functions/mckinsey-digital/ourinsights/the-big-boost-how-incumbents-successfully-scale-their-new-businesses

Bellamy LC, Amoo N, Mervyn K, \& Hiddleston-Mumford J. 2019. "The use of strategy tools and frameworks by SMEs in the strategy formation process". International Journal of Organizational Analysis, Vol.27, N.2, pp.337-367.

Booth A, Patel N, \& Smith M. 2020. "Digital transformation in energy: Achieving escape velocity", McKinsey \& Company. Retrieved from https://www.mckinsey.com/industries/oil-andgas/our-insights/digital-transformation-in-energy-achieving-escape-velocity

Bosma N, \& Stam E. 2012. "Local Policies for High-Employment Growth Enterprises". OECD/DBA International Workshop, Copenhagen, 28th March 2012. 
Boström E, \& Celik OC. 2017. 'Towards a maturity model for digital strategizing: A qualitative study of how an organization can analyze and assess their digital business strategy'. Dissertation, Dept. of Informatics, Umeå University.

Bradley C, Hirt M, \& Smit S. 2018. "Strategy Beyond the Hockey Stick: People, Probabilities, and Big Moves to Beat the Odds". Wiley, New Jersey, USA.

Bucy M, Hall S, \& Yakola D. 2016. "Transformation with a capital T". McKinsey Quarterly, November 2016.

Bughin J, LaBerge L, \& Mellbye A. 2017. "The case for digital reinvention". McKinsey Quarterly, Vol.2, pp.1-15.

Burke GT, \& Wolf C. (2021). "The process affordances of strategy toolmaking when addressing wicked problems". Journal of Management Studies, Vol.58, N.2, pp.359-388.

Calandro J, \& Lane S. 2007. "A new competitive analysis tool: the relative profitability and growth matrix". Strategy \& Leadership, Vol.35, N.2, pp.30-38.

Capron L, \& Mitchell W. 2012. "Build, Borrow, or Buy: Solving the Growth Dilemma". Harvard Business Review Press, Brighton, Massachusetts, USA.

Cherrayil NK. 2020. "Microsoft acquires more unicorns among big five technology companies". Techradar, $27^{\text {th }}$ June 2020. Retrieved from https://www.techradar.com/news/microsoft-acquiresmore-unicorns-among-big-five-technology-companies

Chesbrough HW. 2002. "Making sense of corporate venture capital". Harvard Business Review, Vol.80, N.3, pp.90-99.

Chesbrough HW. 2003. "The era of open innovation". MIT Sloan Management Review, Vol.44, N.3, pp.35-41.

Chesbrough HW. 2011. "Everything You Need to Know About Open Innovation”. Forbes, March 21st, 2011. Retrieved from https://www.forbes.com/sites/henrychesbrough/2011/03/21/ everything-you-need-to-know-about-open-innovation/

Christensen CM, \& Raynor ME. 2003. "The Innovator's Solution: Creating and Sustaining Successful Growth". Harvard Business Review Press, Brighton, Massachusetts, USA.

Cohen S, \& Hochberg YV. 2014. "Accelerating Startups: The Seed Accelerator Phenomenon". SSRN Electronic Journal, pp.1-16.

Contractor FJ, \& Lorange P. 2002. "Cooperative Strategies and Alliances". Emerald Group Publishing, Bingley, UK.

Crabb J. 2018. "What banks need for digital transformation". International Financial Law Review., November 2nd.

Creswell JW, \& Creswell JD. 2017. "Research Design: Qualitative, Quantitative, and Mixed Methods Approaches", 5th Edition. SAGE Publishing, New York, USA.

Cuatrecasas P. 2019. "Go Tech, or Go Extinct: How Acquiring Tech Disruptors Is the Key to Survival and Growth for Established Companies". Berkeley Street Press, USA. 
De Armond C. 2015. "A piecemeal approach to digital innovation won't work". Accenture. Retrieved from https://insuranceblog.accenture.com/a-piecemeal-approach-to-digitalinnovation-wont-work

De Raedemaecker S, Handscomb C, Jautelat S, Rodriguez M, \& Wienke L. 2020. "Lean management or agile? The right answer may be both". McKinsey \& Company, July 2020. Retrieved from https://www.mckinsey.com/business-functions/operations/our-insights/leanmanagement-or-agile-the-right-answer-may-be-both

Deichmann D, Rozentale I, \& Barnhoorn R. 2017. “Open Innovation Generates Great Ideas, So Why Aren't Companies Adopting Them?”. Harvard Business Review, December 20th.

Deloitte. 2019. "Starting your modernization journey- Update legacy systems with fully automated migration". Deloitte. Retrieved from https://www2.deloitte.com/content/dam/Deloitte/us/Documents/technology/us-starting-yourmodernization-journey.pdf

Desmet D, Duncan E, Scanlan J, \& Singer M. 2015, 'Six building blocks for creating a highperforming digital enterprise', McKinsey \& Company, September $1^{\text {st }}, 2015$. Retrieved from https://www.mckinsey.com/business-functions/organization/our-insights/six-building-blocksfor-creating-a-high-performing-digital-enterprise

Díaz T. 2020. "Galp se lanza al autoconsumo con EI, una nueva filial de corte tecnológico". El Economista, 8th October 2020. Retrieved from https://www.eleconomista.es/empresasfinanzas/noticias/10815699/10/20/Galp-se-lanza-al-autoconsumo-con-EI-una-nueva-filial-decorte-tecnologico.html

Dubois A, \& Gadde LE. 2002. "Systematic combining: an abductive approach to case research". Journal of Business Research, Vol.55, N.7, pp.553-560.

Dushnitsky G. 2006. "Corporate venture capital: past evidence and future directions". In: Classon W, Yeung B, Basu A, \& Wadeson N (eds). "The Oxford handbook of entrepreneurship". Oxford University Press, Oxford, England, pp.387-431.

Dushnitsky G, \& Lenox MJ. 2005. "When do incumbents learn from entrepreneurial ventures? Corporate venture capital and investing firm innovation rates". Research Policy, Vol.34, N.5, pp.615-639.

Eagar R, Webster P, Kilefors P, \& Sandeberg I. 2019. "The next generation of corporate incubators". Technology \& innovation management, N.2, 2019, Arthur D Little. Retrieved from https://www.adlittle.com/en/insights/prism/the-next-generation-of-corporate-incubators

Easton G. 1995. "Case research as a methodology for industrial networks: a realist apologia". Proceedings from the 11th IMP Conference, Manchester. Manchester: Manchester Federal School of Business and Management, pp.368-91.

Eisenhardt KM. 1989. "Building theories from case study research". Academy of Management Review, Vol.14, N.4, pp.532-550.

Elliott S. 2020. "IOCs committed to helping drive energy transition; gas has key role: industry". S\&P Global, September $7^{\text {th }}$ 2020. Retrieved from https://www.spglobal.com/platts/en/marketinsights/latest-news/coal/090720-iocs-committed-to-helping-drive-energy-transition-gas-haskey-role-industry 
Elliott T. 2017. "Digital Transformation Is About How, Not What". SAP. Retrieved from https://news.sap.com/2017/10/digital-transformation-is-about- how-not-what/

Ernst H, Witt P, \& Brachtendorf G. 2005. "Corporate venture capital as a strategy for external innovation: an exploratory empirical study". R\&D Management, Vol.35, N3, pp.233-242.

Flyvbjerg B. 2006. "Five misunderstandings about case-study research". Qualitative Inquiry, Vol.12, N.2, pp.219-245.

Garel G. 2015. "Lessons in Creativity from the Innovative Design of the Swatch". Technology Innovation Management Review, Vol.5, N.7, pp.34-40.

Glaser BG, \& Strauss AL. 1967. "The Discovery of Grounded Theory: Strategies for Qualitative Research". Aldine, Chicago, USA.

Gobillot E. 2016. "The Connected Leader: Creating Agile Organizations for People Performance and Profit". Kogan Page, London, UK.

Golafshani N. 2003. "Understanding reliability and validity in qualitative research". The qualitative report, Vol.8, N.4, pp.597-607.

Goodpasture JC. 2010. "Project Management the Agile Way: Making it Work in the Enterprise". J. Ross Publishing, Plantation, Florida, USA.

Goold M, Campbell A, \& Alexander M. 1994. "Corporate-Level Strategy: Creating Value in the Multibusiness Company". Wiley, New York, USA.

Gupta S. 2018. "Driving Digital Strategy". Harvard Business Review Press, Brighton, Massachusetts, USA.

Gutmann T. 2019. "Harmonizing corporate venturing modes: an integrative review and research agenda". Management Review Quarterly, Vol.69, N.2, pp.121-157.

Hambrick DC. 2007. "Upper echelons theory: an update". Academy of Management Review, Vol.32, N.2, pp.334-343.

Hawash B, Abuzawayda YI, Mokhtar UA, Yusof ZM, \& Mukred M. 2020. "Digital transformation in the oil and gas sector during covid-19 pandemic". International Journal of Management, Vol.11, N.12, pp.725-735.

Henderson BD. (1970). "The product portfolio". Boston: The Boston Consulting Group.

Hoffmann DL, \& Radojevich-Kelley N. 2012. "Analysis of Accelerator Companies: An Exploratory Case Study of Their Programs, Processes, and Early Results". Small Business Institute Journal, Vol.8, N.2, pp.54-70.

Jarzabkowski P, \& Kaplan S. (2015). "Strategy tools-in-use: A framework for understanding "technologies of rationality" in practice". Strategic Management Journal, Vol.36, N.4, pp.537558.

Kanbach DK, \& Stubner S. 2016. "Corporate Accelerators As Recent Form Of Startup Engagement: The What, The Why, And The How". Journal of Applied Business Research, Vol.32, N.6, pp.1761-1776. 
Kane GC, Palmer D, Phillips AN, Kiron D, \& Buckley N. 2016. "Aligning the organization for its digital future". MIT Sloan Management Review, Vol.58, N.1.

Kane GC, Phillips AN, Copulsky JR, \& Andrus GR. 2019. "The Technology Fallacy: How People Are the Real Key to Digital Transformation”. MIT Press, Cambridge, Massachusetts, USA.

Karimi J, \& Walter Z. 2015. "The Role of Dynamic Capabilities in Responding to Digital Disruption: A Factor-Based Study of the Newspaper Industry". Journal of Management Information Systems, Vol.32, N.1, pp.39-81.

Kazim F. 2019. "Digital Transformation and Leadership Style: A Multiple Case Study". The ISM Journal of International Business, Vol.3, N.1, pp.24-33.

Khalaf R, Raval A, \& Sheppard D. 2020. "BP's Looney stakes future on producing less oil". Financial Times, September $13^{\text {th }} 2020$. Retrieved from https://www.ft.com/content/e1d53208b460-4708-a89c-d8b418cceffb

Knight E, Paroutis S, \& Heracleous L. (2018). "The power of powerpoint: A visual perspective on meaning making in strategy". Strategic Management Journal, Vol.39, N.3, pp.894-921.

Kohler T. 2016. "Corporate accelerators: building bridges between corporations and start-ups". Business Horizons, Vol.59, N.3, pp.347-357.

Kullik O, Hölzle K, Halecker B, \& Hartmann M. 2018. "Company Building - A New Phenomenon of Corporate Venturing?". The International Society for Professional Innovation Management (ISPIM) Innovation Symposium, June 2018, Manchester, pp.1-9.

Lakhani KR, Iansiti M, \& Herman K. 2014. "GE and the Industrial Internet”. Harvard Business School, Case 614-032.

Lammey M. 2020. "BP's unicorn seeker not afraid to back the occasional wrong horse". Energy Voice, $23^{\text {rd }}$ January 2020. Retrieved from

https://www.energyvoice.com/otherenergy/219707/bps-unicorn-seeker-not-afraid-to-back-the-

occasional-wrong-horse/

Llewellyn R. 2019. "Transformation Through Acquisition”. Transformation Management Series. Retrieved from https://robllewellyn.com/transformation-through-acquisition/

Loucks J, Macaulay J, Noronha A, \& Wade M. 2016. "Digital Vortex: How Today's Market Leaders Can Beat Disruptive Competitors at Their Own Game". DBT Center Press, Lausanne, Switzerland.

Lowy A, \& Hood P. 2010. "The Power of the 2 x 2 Matrix: Using 2 x 2 Thinking to Solve Business Problems and Make Better Decisions". Wiley, Hoboken, New Jersey, USA.

Lu H, Guo L, Azimi M, \& Huang K. 2019. "Oil and Gas 4.0 era: A systematic review and outlook". Computers in Industry, Vol.111, pp.68-90.

Malek K, Maine E, \& McCarthy IP. 2014. "A typology of clean technology commercialization accelerators". Journal of Engineering and Technology Management, Vol.32, pp.26-39.

Malhotra A, Majchrzak A, Kesebi L, \& Looram S. 2017. "Developing Innovative Solutions Through Internal Crowdsourcing”. MIT Sloan Management Review, Vol. 58, N.4, pp.73-79. 
Mas-Verdú F, Ribeiro-Soriano D, \& Roig-Tierno N. 2015. "Firm survival: The role of incubators and business characteristics". Journal of Business Research, Vol.68, N.4, pp.793-796.

Maula MVJ, Autio E, \& Murray GC. 2005. "Corporate venture capitalists and independent venture capitalists: what do they know, who do they know and should entrepreneurs care?". In: Elfring T. (eds) "Corporate Entrepreneurship and Venturing". International Studies in Entrepreneurship, Vol.10. Springer, Boston, MA, USA.

Mazzone DM. 2014. "Digital or Death: Digital Transformation: The Only Choice for Business to Survive Smash and Conquer". Smashbox Consulting Inc., Mississauga, Canada.

McCall MW. 1998. "High Flyers: Developing the Next Generation of Leaders". Harvard Business School Press, Boston, Massachusetts, USA.

Mhlungu NSM, Chen JYJ, \& Alkema P. 2019. "The underlying factors of a successful organisational digital transformation". South African Journal of Information Management, Vol.21, N.1, pp.1-10.

Moroz M. 2018. “Acceleration of Digital Transformation as a result of launching programs financed from public funds: Assessment of implementation of the operational program Digital Poland". Foundations of Management, Vol.10, N.1, pp.59-74.

Morse J, Barrett M, Mayan M, Olson K \& Spiers J. 2008. "Verification strategies for establishing reliability and validity in qualitative research". International Journal of Qualitative Methods, Vol.1, N.2, pp.13-22.

Narsalay R, Qiu SJ, \& An S. 2015. "Open Innovation: Collaborating successfully with small hightech firms". Accenture Institute for High Performance. Retrieved from https://www.accenture.com/_acnmedia/Accenture/Conversion-

Assets/DotCom/Documents/Global/PDF/Dualpub_25/Accenture-Open-Innovation-and-

Collaboration-Executive-Summary-English_(secured).pdf

Nel K, Furr N, \& Ramsoy TZ. 2018. "Leading Transformation: How to Take Charge of Your Company's Future". Harvard Business Review Press, Brighton, Massachusetts, USA.

Obwegeser N, Tomoko Yokoi T, Michael Wade M, \& Voskes T. 2020. "7 Key Principles to Govern Digital Initiatives”. MIT Sloan Management Review, Vol.1, N.3, pp.1-9.

Oswald G, \& Kleinemeier M, (eds.). 2017. 'Shaping the digital enterprise'. Springer International Publishing, Berlin.

Paroutis S, Franco LA, \& Papadopoulos T. (2015). "Visual interactions with strategy tools: Producing strategic knowledge in workshops". British Journal of Management, Vol.26, S48-S66.

Pauwels C, Clarysse B, Wright M, \& Van Hove J. 2016. "Understanding a new generation incubation model: The accelerator". Technovation, Vol.50-51, pp.13-24.

Pershina R, Soppe B, Thune TN. 2019. "Bridging Analog and Digital Expertise: Cross-Domain Collaboration and Boundary-Spanning Tools in the Creation of Digital Innovation". Research Policy, Vol.48, N.9. 
Pidun U, Rubner H, Kruehler M, Untiedt R, \& Nippa M. (2011). "Corporate portfolio management: Theory and practice". Journal of Applied Corporate Finance, Vol.23, N.1, pp.6376.

Pohlisch J. 2020. "Internal Open Innovation-Lessons Learned from Internal Crowdsourcing at SAP”. Sustainability, Vol.12, N.10, pp.4245.

Potts B. 2020. "Thinking Beyond the Barrel: How Galp Increased Agility Through Business Transformation". Blog SAP. Retrieved from https://blogs.sap.com/2020/06/18/thinking-beyondthe-barrel-how-galp-increased-agility-through-business-transformation/

Rigby DK, Sutherland J, \& Takeuchi H. 2016. "Embracing Agile". Harvard Business Review, May 2016.

Röhm P. 2018. "Exploring the landscape of corporate venture capital: a systematic review of the entrepreneurial and finance literature". Management Review Quarterly, Vol.68, N.3, pp.279-319.

Rolland KH, Mathiassen L, \& Rai A. 2018. "Managing digital platforms in user organizations: the interactions between digital options and digital debt". Information Systems Research, Vol. 29, N.2, pp.419-443.

Sahakitpinyo K. 2020. "Stakeholder influence and business models in corporate-accelerators: a conceptual framework". The International Society for Professional Innovation Management (ISPIM) Conference Proceedings; Manchester, England.

Saldanha T. 2019. "Why Digital Transformations Fail. The surprising disciplines of how to take off and stay ahead". Berrett-Koehler Publishers, Oakland, California, USA.

Sampson RC. 2007. "R\&D alliances and firm performance: The impact of technological diversity and alliance organization on innovation". Academy of Management Journal, Vol.50, N.2, pp.364386.

Sandberg J, Mathiassen L, \& Napier N. 2014. "Digital options theory for IT capability investment". Journal of the Association for Information Systems, Vol.15, N.7, pp.422-453.

Saunders B, Sim J, Kingstone T, Baker S, \& Waterfield J. 2018. "Saturation in qualitative research: exploring its conceptualization and operationalization". Quality and Quantity, Vol.52, N.4, pp. 1893-1907.

Scheuplein C, \& Kahl J. 2017. "Do Company Builders Create Jobs? Examining the Rise of Incubation Finance in Germany". SSRN Electronic Journal, pp.1-19.

Schwartz M. 2013. "A control group study of incubators' impact to promote firm survival". The Journal of Technology Transfer, Vol.38, N.3, pp.302-331.

Seidl D, \& Whittington R. 2014. "Enlarging the Strategy-as-Practice Research Agenda: Towards Taller and Flatter Ontologies". Organization Studies, Vol.35, N.10, pp.1407-1421.

Shakina E, Parshakov P, \& Alsufiev A. 2021. "Rethinking the corporate digital divide: the complementarity of technologies and the demand for digital skills". Technological Forecasting and Social Change, Vol.162, 120405. 
Siggelkow N, \& Terwiesch C. 2019. "Connected Strategy: building continuous customer relationships for competitive advantage". Harvard Business Review Press, Boston, Massachusetts, USA.

Silva B. 2019. "Galp lança nova empresa Flow para promover mobilidade elétrica e car sharing". Dinheiro Vivo, 10th October 2019. Retrieved from https://www.dinheirovivo.pt/economia/galplanca-nova-empresa-flow-para-promover-mobilidade-eletrica-e-car-sharing/

Skarzynski P, \& Gibson R. 2008. "Innovation to the Core: A Blueprint for Transforming the Way Your Company Innovates". Harvard Business Review Press, Brighton, Massachusetts, USA.

Spee AP, \& Jarzabkowski P. (2009). "Strategy tools as boundary objects". Strategic Organization, Vol.7, N.2, pp.223-232.

Spooner JG. (2004). "IBM sells PC group to Lenovo". Retrieved from https://www.cnet.com/news/ibm-sells-pc-group-to-lenovo/

Strauss A. 1987. "Qualitative analysis for social scientists". Cambridge University Press, Cambridge, England.

Tabrizi B, Lam E, Girard K, \& Irvin V. 2019. "Digital Transformation Is Not About Technology". Harvard Business Review. Retrieved from https://hbr.org/2019/03/digital-transformation-is-notabout-technology

Teixeira T. 2019. "Unlocking the Customer Value Chain: How Decoupling Drives Consumer Disruption”. Penguin Random House, New York, USA.

Thompson, A, Peteraf, M, Gamble J, \& Strickland A. 2012. "Crafting \& executing strategy: The quest for competitive advantage”. McGraw-Hill-Irwin, Chicago, Illinois, USA.

Tijan E, Jović M, Aksentijević S, \& Pucihar A. 2021. "Digital transformation in the maritime transport sector". Technological Forecasting and Social Change, Vol.170, 120879.

Tung TV, Trung TN, Hai NH, \& Tinh NT. 2020. "Digital transformation in oil and gas companies- A case study of Bien Dong POC". Petrovietnam Journal, Vol.10, pp.67-78.

Tushman ML, \& O'Reilly III CA. 2004. "The ambidextrous organization”. Harvard Business Review, Boston, MA, USA.

Vaughan A. 2018. "BP buys UK's biggest electric car charger network for £130m”. The Guardian, 28th June 2018. Retrieved from https://www.theguardian.com/business/2018/jun/28/bp-buys-uks-biggest-electric-car-chargernetwork-for-130m

Verhoef PC, Broekhuizen T, Bart Y, Bhattacharya A, Dong JQ, Fabian N, \& Haenlein M. 2021. "Digital transformation: A multidisciplinary reflection and research agenda". Journal of Business Research, Vol. 122, pp.889-901.

Vial G. 2019. "Understanding digital transformation: A review and a research agenda". The Journal of Strategic Information Systems, Vol.28, N.2, pp.118-144.

Wade M. 2015. "Digital Business Transformation- A Conceptual Framework". Global Center for Digital Business Transformation, IMD. 
Wade M, Macaulay J, Noronha A, \& Barbier J. 2019. "Orchestrating Transformation: How to Deliver Winning Performance with a Connected Approach to Change". DBT Center Press, Lausanne, Switzerland.

Wanasinghe TR, Wroblewski L, Petersen BK, Gosine RG, James LA, De Silva O, Mann GKI, \& Warrian PJ. 2020a. "Digital Twin for the Oil and Gas Industry: Overview, Research Trends, Opportunities, and Challenges". IEEE access, Vol.8, pp.104175-104197.

Wanasinghe TR, Gosine RG, James LA, Mann GK, de Silva O, \& Warrian PJ. 2020b. "The Internet of Things in the Oil and Gas Industry: A Systematic Review". IEEE Internet of Things Journal, Vol.7, N.9, pp. 8654-8673.

Wind Y. 1974. "Product Portfolio: A New Approach to the Product Mix Decision,". In Curhan RC, ed., Combined Proceedings (Chicago: American Marketing Association, 1974), pp. 460-464.

Weick KE. 1969. "The social psychology of organizing". Addison-Wesley, Boston, Massachusetts, USA.

Weiblen T, \& Chesbrough HW. 2015. "Engaging with start-ups to enhance corporate innovation". California Management Review, Vol.57, N.2, pp.66-90.

Whittington R. 2006. "Completing the practice turn in strategy research". Organization Studies, Vol.27, N.5, pp.613-634.

World Economic Forum. 2017. "Digital Transformation Initiative- Oil and Gas Industry". WEF White Papers. Retrieved from https://reports.weforum.org/digital-transformation/wpcontent/blogs.dir/94/mp/files/pages/files/dti-oil-and-gas-industry-white-paper.pdf

Wright RP, Paroutis SE, \& Blettner DP. (2013). "How useful are the strategic tools we teach in business schools?”. Journal of Management Studies, Vol.50, N.1 pp.92-125.

Wright RV. 1978. "A System for Managing Diversity”. In Britt SH \& Boyd H., eds., Marketing Management and Administrative Action. McGraw-Hill, New York, USA.

Yin R. 1994. "Case study research. Design and methods". Sage Publications, Thousand Oaks, California, USA.

Zaki M. 2019. "Digital transformation: harnessing digital technologies for the next generation of services". Journal of Services Marketing, Vol.33, N.4, pp.429-435. 